Полянская И. Л., Белова Л. В.

I. L. Polyanskaya, L.V. Belova ИЗУЧЕНИЕ ВЛИЯНИЯ ТЕМПЕРАТУРЫ ЗАКАЛКИ НА ПРОЦЕССЫ,
ПРОТЕКАЮЩИЕ ПРИ ОТПУСКЕ УГЛЕРОДИСТЫХ СТАЛЕЙ

\title{
STUDY OF THE HARDENING TEMPERATURE INFLUENCE ON PROCESSES WHEN TEMPERING CARBON STEEL
}

Полянская Ирина Леонидовна - кандидат технических наук Уральского государственного университета путей сообщения (филиал в г. Тюмени) (Россия, Тюмень). E-mail: polyanskaya_il@inbox.ru.

Ms. Irina L. Polyanskaya $-\mathrm{PhD}$ in Engineering, Ural State Railway Transport University (affiliated in Tyumen) (Russia, Tyumen). E-mail: polyanskaya_il@inbox.ru.

Белова Лариса Владимировна - старший преподаватель Тюменского индустриального университета (Россия, Тюмень). E-mail: klv@mail.ru.

Ms. Larisa V. Belova - senior lecturer, Industrial University of Tyumen (Russia, Tyumen). E-mail: klv@mail.ru.

Аннотация. В статье представлены результаты исследований изменений электросопротивления углеродистых сталей при низком отпуске и определено влияние температуры на величину электросопротивления Анализ полученных результатов показал, что влияние углерода на величину электросопротивления на несколько порядков выше влияния дефектов кристаллического строения, изменения электросопротивления при отпуске закаленных сталей обусловлены перераспределением углерода.

Summary. The article presents the research results of carbon steel electrical resistance changes at low tempering and determines the effect of temperature on the electrical resistance. The analysis of the results showed that the influence of carbon on the value of the electrical resistance is higher than the influence of the crystal structure defects. The changes of the hardened steel electrical resistance are due to the redistribution of carbon.

Ключевые слова: закалка, температура закалки, температура отпуска, электросопротивление, удельное электросопротивление, закаленные стали.

Key words: hardening, hardening temperature, tempering temperature, electrical resistance, electrical resistivity, hardened steel.

УДК 669.111.35:539.4.015

\section{Введение}

Для надежной работы узлов механизмов трения и качения большое значение имеют их закалка и отпуск. Исследователи применяли различные температуры закалки для сталей практически одинакового состава. Так как температура закалки определяет степень растворения карбидов хрома в аустените, представляется интересным проследить влияние температуры закалки и степени растворения карбидов на процессы, протекающие при отпуске сталей.

\section{Методика проведения исследований}

Величину электросопротивления можно изучать как величину, отражающую не только внутренние превращения, возникающие при закалке, отпуске, изотермическом распаде аустенита и тому подобных обработках, но и явления, происходящие при дисперсионном твердении ферритных и аустенитных сталей, не испытывающих аллотропических превращений [4].

Измерение электросопротивления проводилось потенциометрическим методом на стандартной установке. В конструкцию установки по измерению электросопротивления были внесены изменения, после чего на ней стало возможным определять абсолютные значения электросопротивления одновременно у четырех образцов [8;9]. 
Узел для размещения образцов представлен на рис. 1. Образцы 1 размещались в кварцевой трубке 6. Расстояние до всех четырех предметов от стенок трубки было одинаковым. К ним через керамические трубки 2 подводились токовые 4 и потенциальные 5 провода. Провода приваривались к образцам конденсаторной сваркой. Для получения равномерной температуры в зоне, где они находились, применялись экраны 3 из нержавеющей стали. Температура в этой зоне замерялась термопарой 8. Для получения вакуума не ниже 10 мм рт.ст. кварцевая трубка имела фланцевый затвор 7. Размер образцов для измерения электросопротивления составлял $2 \times 2 \times 2$ мм.
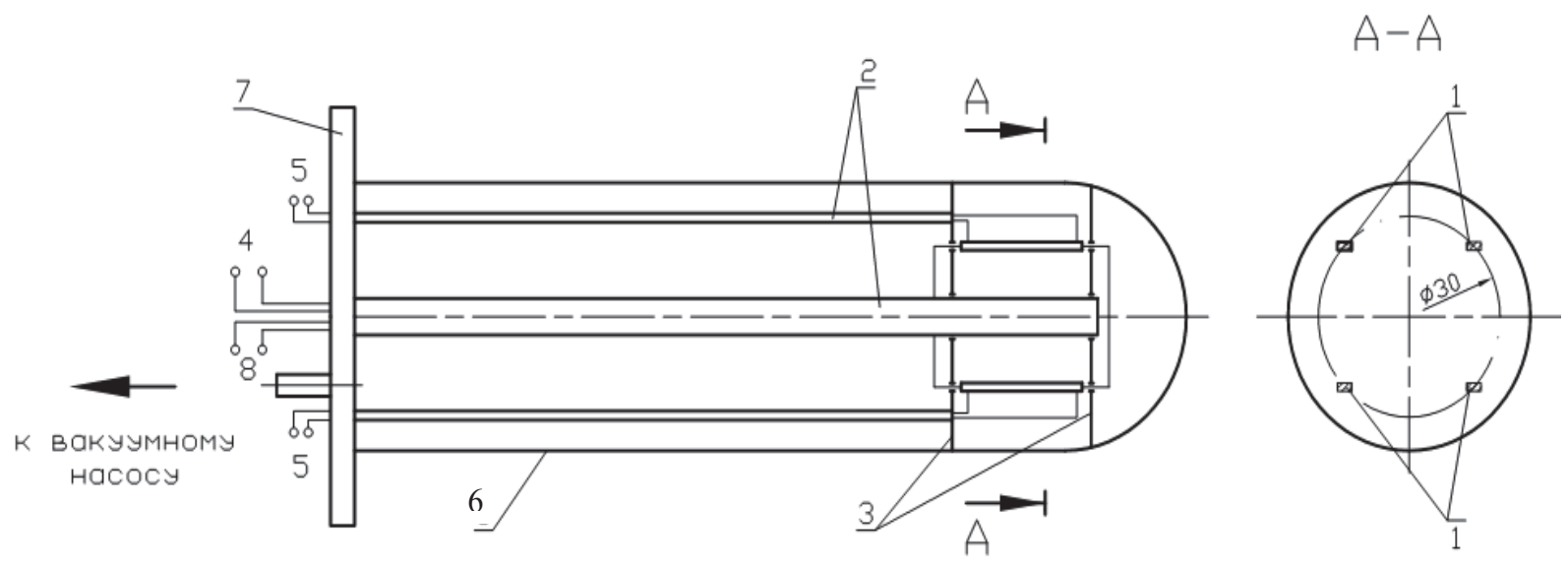

Рис. 1. Схема расположения образцов в кварцевой трубке при измерении электросопротивления:

1 - образцы; 2 - керамические трубки для токовых и потенциальных проводов;

3 - экраны из нержавеющей стали; 4 - токовые провода;

5 - потенциальные провода; 6 - кварцевая трубка; 7 - фланцевый затвор; 8 - термопара

Исследование проводилось на углеродистой стали 35 и хромистой стали $35 \mathrm{X} 4$. Образцы этих сплавов нагревали в кварцевых трубках до различных температур $\left(850,950,1100\right.$ и $\left.1200{ }^{\circ} \mathrm{C}\right)$. Выдержка при нагреве до заданной температуры составляла 30 мин. Часть образцов обрабатывали по режиму $+1200{ }^{\circ} \mathrm{C}$ в течение 4 ч. Охлаждение их проводили в $20 \%$-ном растворе щелочи $\mathrm{NaOH}$.

Температурная зависимость электросопротивления снималась в процессе циклического отпуска. Суть циклического отпуска заключалась в том, что образцы последовательно нагревали до различных температур, причем температурный интервал при отпуске составлял $25^{\circ} \mathrm{C}$.

Измерение электросопротивления производилось следующим образом. Вначале замерялось исходное значение электросопротивления при комнатной температуре $\left(+20{ }^{\circ} \mathrm{C}\right)$ у закаленных образцов, затем производился их последовательный нагрев до нужных температур. После каждого нагрева образцы охлаждались до $+20^{\circ} \mathrm{C}$ и замерялось значение электросопротивления.

Время выдержки при нагреве сталей до заданной температуры составляло 5 мин, после чего образец охлаждали до комнатной температуры и проводили измерения значений электросопротивления.

Данная схема измерения электросопротивления имеет ряд преимуществ. Во-первых, влияние отпуска на распад мартенсита закаленных сталей здесь изучается на одном образце, что исключает погрешности, которые неизбежно возникают, если брать на каждую температуру по свежему образцу. Смена образца повлечет за собой разброс значений электросопротивления из-за изменения расстояния между потенциальными проводами за счет различий в химическом составе, условиях закалки, геометрии образцов и качестве контакта потенциальных проводов с ними. Во-вторых, эта схема измерения позволяет выявить влияние изменений в структуре образца на электросопротивление. Снимая зависимость электросопротивления образца от температуры отпуска при непрерывном нагреве, не удается получить такой четкой зависимости потому, что влия- 
ние температуры нагрева на электросопротивление на порядок больше, чем влияние структурных факторов.

О влиянии температуры закалки и отпуска на электросопротивление судили по величине

$$
\frac{\Delta R}{R_{0}}
$$

где $\Delta R=\frac{R_{0}-R_{T}}{R_{0}}-$ электросопротивление закаленного образца при комнатной температуре, здесь $R_{T}$ - электросопротивление образца при комнатной температуре после нагрева; $R_{0}$ - электросопротивление закаленного образца при комнатной температуре после нагрева.

Для того чтобы более четко показать влияние температуры отпуска на величину электросопротивления, определяли температурный коэффициент электросопротивления. Величину температурного коэффициента электросопротивления рассчитывали по формуле [8; 3 ]

$$
\alpha_{R}=\frac{\Delta R_{T}}{\Delta T} \cdot \frac{1}{R_{0}},
$$

где $\Delta R_{T}=R_{T l}-R_{T 2}, \Delta T=T_{l}-T_{2}$. При этом $R_{T l}$ и $R_{T 2}, T_{l}$ и $T_{2}$ - текущие значения электросопротивления и температуры.

\section{Результаты исследований}

Нагрев до высоких температур при закалке приводит к значительным изменениям в структуре стали. Растет зерно, изменяется морфология мартенсита, увеличивается количество дефектов кристаллического строения, происходит перераспределение элементов в твердом растворе и т.д. Все эти факторы оказывают существенное влияние на процессы, протекающие при отпуске. Добавление хрома в сталь в значительной степени изменяет ее структуру, поэтому перед рассмотрением хромистых сталей нами была поставлена задача - исследовать влияние температуры закалки на процессы, протекающие при отпуске простой углеродистой стали.

Отражено влияние температуры закалки на величину удельного электросопротивления закаленных сталей.

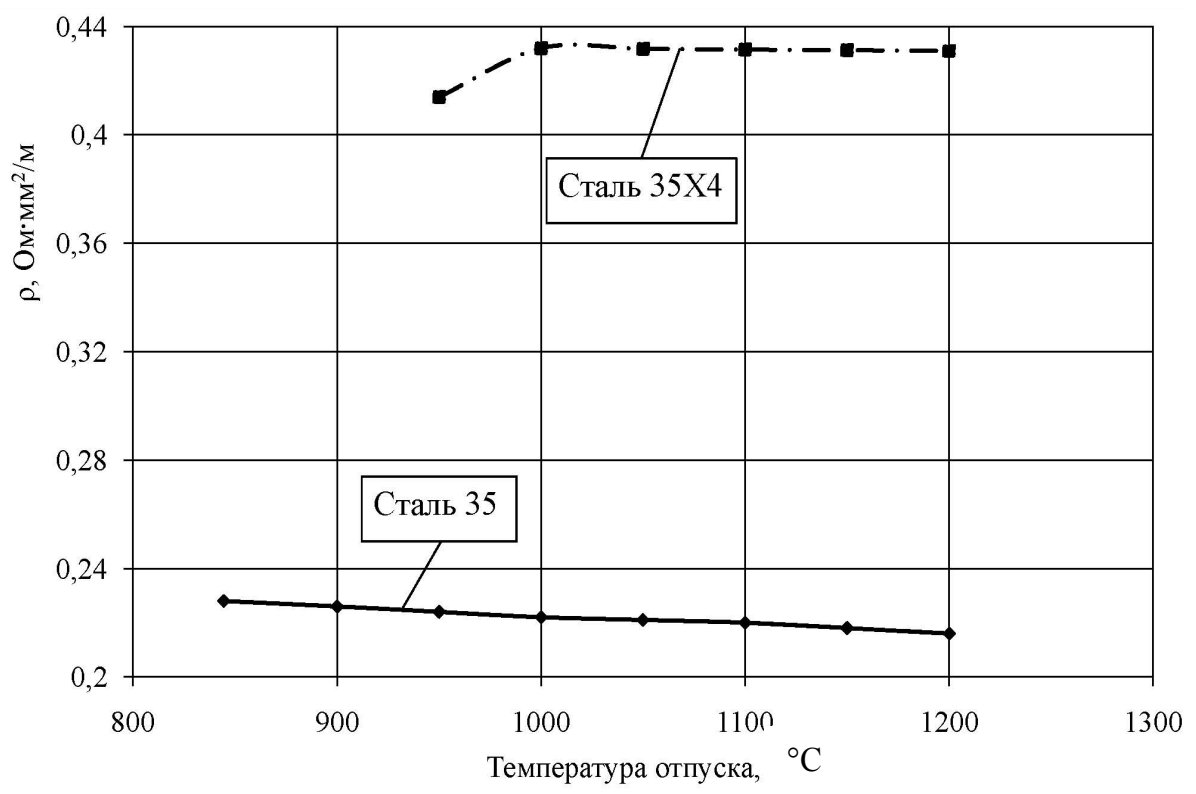

Рис. 2. Влияние температуры закалки на удельное электросопротивление стали 35

(сталь 35X4 приведена для сравнения) 
Как видно из рис. 2 (кривая 1), электросопротивление стали 35 с повышением температуры закалки немного уменьшается.

На рис. 3 и 4 показано влияние температуры отпуска на величину удельного сопротивления для сталей 35 и $35 \mathrm{X} 4$ соответственно.

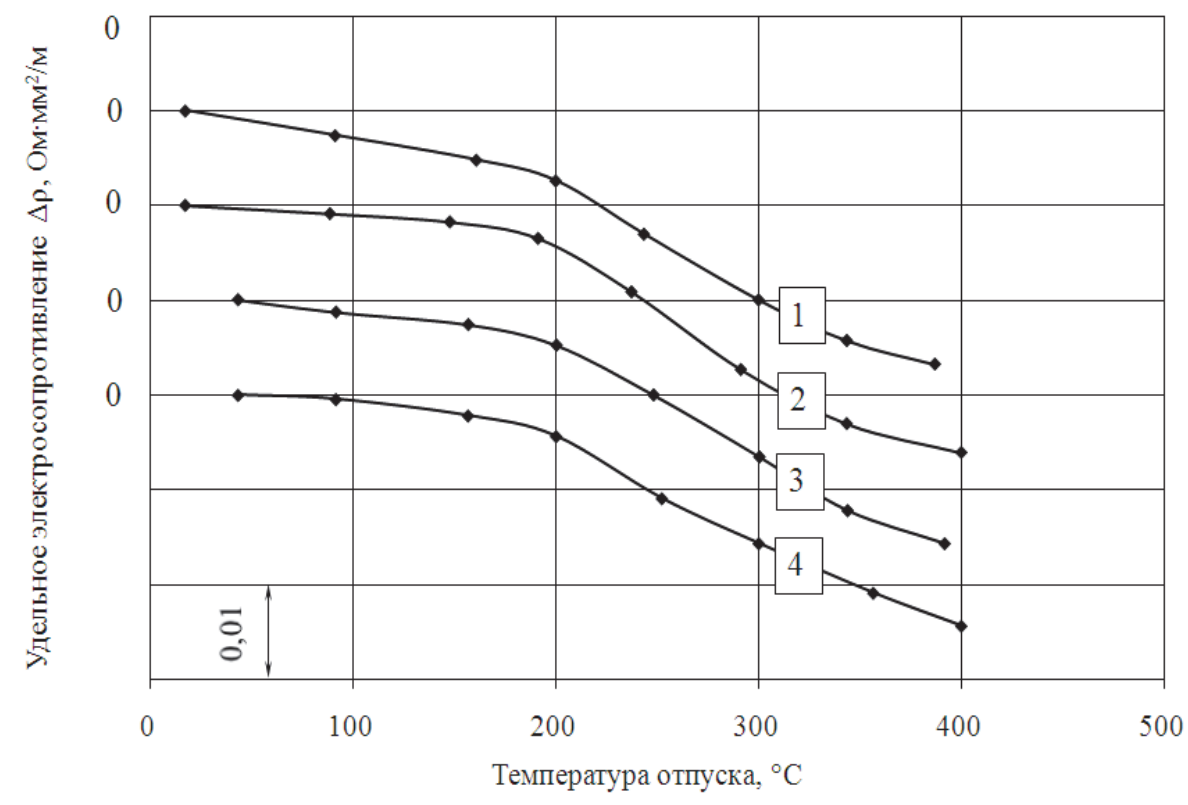

Рис. 3. Влияние температуры отпуска на удельное сопротивление $\rho$ стали 35 , закаленной с различных температур (выдержка при температуре закалки 4 ч): $1-850{ }^{\circ} \mathrm{C} ; 2-950{ }^{\circ} \mathrm{C} ; 3-1100{ }^{\circ} \mathrm{C} ; 4-1200{ }^{\circ} \mathrm{C}$

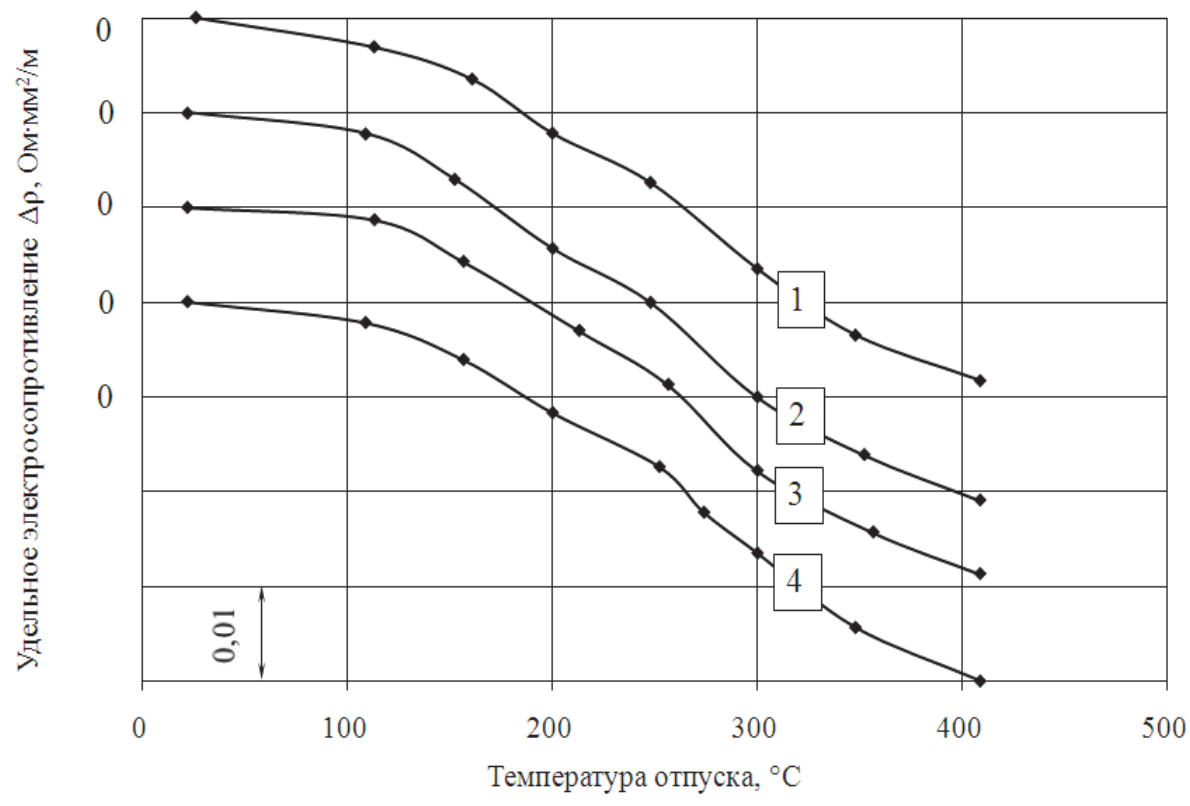

Рис. 4. Влияние температуры отпуска на удельное электросопротивление $\rho$ стали $35 \mathrm{X} 4$, закаленной с различных температур (выдержка при температуре закалки 4 ч):

$$
1-850{ }^{\circ} \mathrm{C} ; 2-950{ }^{\circ} \mathrm{C} ; 3-1100{ }^{\circ} \mathrm{C} ; 4-1200{ }^{\circ} \mathrm{C}
$$


Полянская И. Л., Белова Л. В.

ИЗУЧЕНИЕ ВЛИЯНИЯ ТЕМПЕРАТУРЫ ЗАКАЛКИ НА ПРОЦЕССЫ, ПРОТЕКАЮЩИЕ ПРИ ОТПУСКЕ УГЛЕРОДИСТЫХ СТАЛЕЙ

Влияние на величину температурного коэффициента электросопротивления образцов, закаленных с различных температур, представлено для сталей 35 и 35X4 на рис. 5, 6 соответственно.

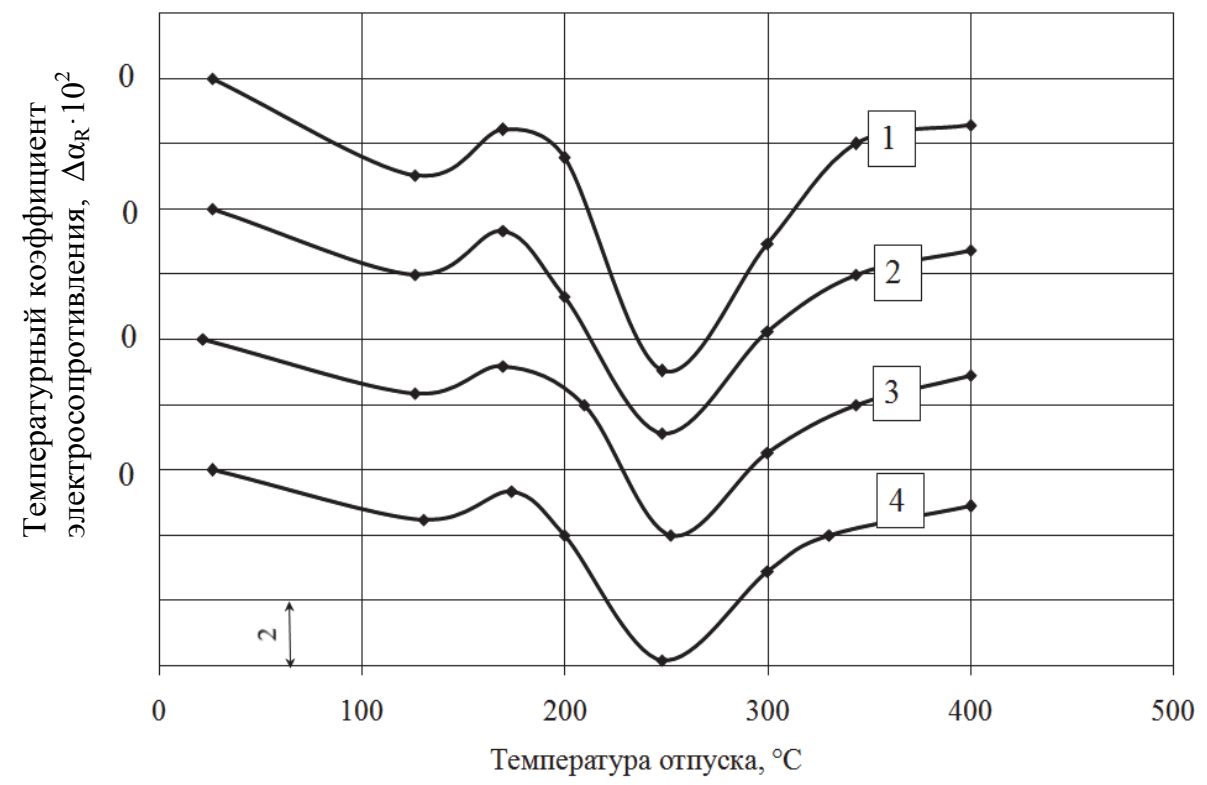

Рис. 5. Влияние температуры отпуска на величину температурного коэффициента электросопротивления $\alpha_{R}$ стали 35 , закаленной с различных температур (выдержка при температуре закалки 4 ч): $1-850{ }^{\circ} \mathrm{C} ; 2-950{ }^{\circ} \mathrm{C} ; 3-1100{ }^{\circ} \mathrm{C} ; 4-1200{ }^{\circ} \mathrm{C}$

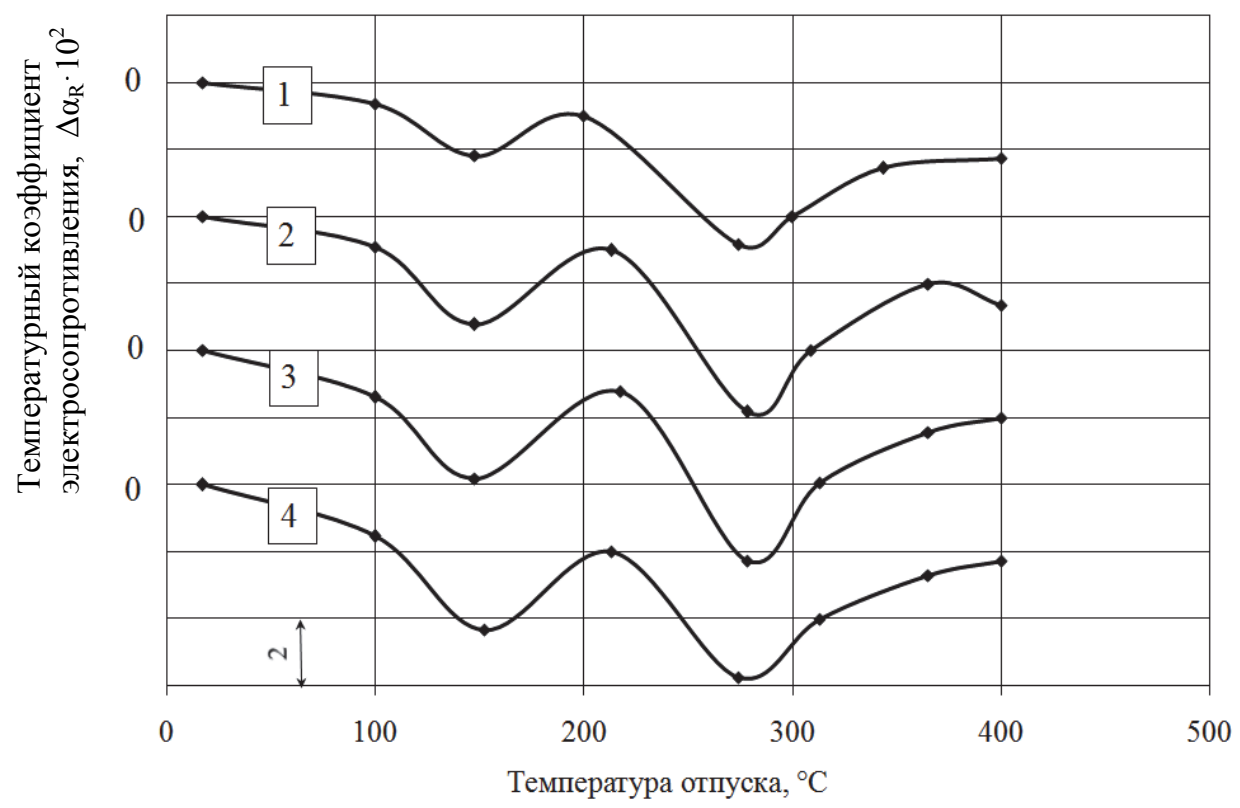

Рис. 6. Влияние температуры отпуска на величину температурного коэффициента электросопротивления $\alpha_{R}$ стали $35 \mathrm{X} 4$, закаленной с различных температур (выдержка при температуре закалки 4 ч): $1-850{ }^{\circ} \mathrm{C} ; 2-950{ }^{\circ} \mathrm{C} ; 3-1100{ }^{\circ} \mathrm{C} ; 4-1200{ }^{\circ} \mathrm{C}$ 
Как видно из данных, приведенных на рис. 5 и 6, электросопротивление закаленной стали 35 при отпуске изменяется немонотонно. Имеются области температур, в которых электросопротивление понижается более интенсивно.

Скорость изменения электросопротивления обусловлена процессами, которые протекают в закаленной стали при нагреве.

Величина температурного коэффициента характеризует скорость изменения электросопротивления. Чем больше эта величина, тем выше скорость падения электросопротивления при отпуске.

Особенно это хорошо видно по изменению величины $\alpha_{R}$. На кривой $\alpha_{R}=f\left(t_{\text {omn }}\right)$ имеются два пика. Первый пик наблюдается в интервале температур $20 \ldots 150{ }^{\circ} \mathrm{C}$, второй - в интервале $200 \ldots 350{ }^{\circ} \mathrm{C}$.

По данным авторов [11; 12], в стали 35 в интервале температур $20 \ldots 150{ }^{\circ} \mathrm{C}$ происходит выделение углерода из $\alpha$-твердого раствора в виде $\varepsilon$-карбида; при интервале температур $200 \ldots 300{ }^{\circ} \mathrm{C}$ $\varepsilon$-карбид переходит в цементит. Согласно $[1 ; 6]$, изменение физических свойств в интервале температур $20 \ldots 150{ }^{\circ} \mathrm{C}$ обусловлено не $\varepsilon$-карбидом, а перераспределением углерода в $\alpha$-твердом растворе и образованием зон, обогащенных углеродом. При температуре от 200 до $300{ }^{\circ} \mathrm{C}$ происходит образование цементита из зон, обогащенных углеродом $[5 ; 8 ; 2]$.

Повышение температуры закалки от 850 до $1200{ }^{\circ} \mathrm{C}$ не изменяет характер температурной зависимости электросопротивления стали 35 при отпуске. Однако вместе с тем видно, что повышение температуры закалки приводит к уменьшению высоты пиков на кривой $\alpha_{R}=f\left(t_{\text {omn }}\right)$. Интересно также отметить, что высота пика в интервале температур $20 \ldots 150{ }^{\circ} \mathrm{C}$ намного ниже высоты пика в интервале $150 \ldots 350^{\circ} \mathrm{C}$.

\section{Обсуждение результатов исследования}

Данные, полученные нами для стали 35 , не позволяют сказать, чем обусловлено изменение электросопротивления в интервале температур $20 \ldots 150{ }^{\circ} \mathrm{C}$ : образованием $\varepsilon$-карбида или образованием зон, обогащенных углеродом. Однако данные по стали $35 \mathrm{X} 4$ свидетельствуют косвенным образом о том, что изменение физических свойств исследуемых сталей при температурном интервале $20 \ldots 150^{\circ} \mathrm{C}$ обусловлено образованием зон, обогащенных углеродом, а не $\varepsilon$-карбидом; поэтому, исследуя изменения физических свойств закаленных сталей при отпуске, будем считать, что при температуре от 20 до $150{ }^{\circ} \mathrm{C}$ происходит образование зон, обогащенных углеродом, а в интервале температур $150 \ldots 350{ }^{\circ} \mathrm{C}$ - образование цементита из зон, обогащенных углеродом.

Повышение температуры закалки от 850 до $1200{ }^{\circ} \mathrm{C}$ не изменяет характер температурной зависимости электросопротивления стали 35 при отпуске. Однако вместе с тем видно, что повышение температуры закалки приводит к уменьшению высоты пиков на кривой $\alpha_{R}=f\left(t_{\text {omn }}\right)$. Интересно также отметить, что высота пика в интервале температур $20 \ldots 150{ }^{\circ} \mathrm{C}$ намного ниже высоты пика в интервале $150 \ldots 350^{\circ} \mathrm{C}$.

\section{Выводы}

Анализ литературных данных по влиянию различных факторов на величину электросопротивления и объемных эффектов в области температур $20 \ldots 150{ }^{\circ} \mathrm{C}$ и $200 \ldots 350{ }^{\circ} \mathrm{C}$ показывает, что его изменение в указанных температурных интервалах обусловлено, главным образом, перераспределением углерода. Это объясняется двумя причинами: во-первых, влияние углерода на электросопротивление на несколько порядков выше влияния дефектов кристаллического строения $[8 ; 3 ; 9]$; во-вторых, в исследуемом интервале температур плотность дефектов кристаллического строения практически не изменяется $[8 ; 3 ; 9]$. То, что изменения электросопротивления при отпуске закаленных сталей обусловлены перераспределением углерода, позволяет по степени изменения этих величин качественно судить о количестве углерода, участвующего в образовании зон в интервале температур $20 \ldots 150^{\circ} \mathrm{C}$ и цементита в интервале $200 \ldots 300^{\circ} \mathrm{C}$.

Уменьшение высоты пиков на кривой $\alpha_{R}=f\left(t_{\text {omn }}\right)$ с повышением температуры закалки свидетельствует об уменьшении количества углерода, принимающего участие в образовании зон и цементита. 
Полянская И. Л., Белова Л. В.

ИЗУЧЕНИЕ ВЛИЯНИЯ ТЕМПЕРАТУРЫ ЗАКАЛКИ НА ПРОЦЕССЫ, ПРОТЕКАЮЩИЕ ПРИ ОТПУСКЕ УГЛЕРОДИСТЫХ СТАЛЕЙ

\section{ЛИТЕРАТУРА}

1. Белоус, М. В. Превращения при отпуске стали / М. В. Белоус, В. Т. Черепин, М. А. Васильев. - М.: Металлургия, 1973. - $230 \mathrm{c.}$

2. Конева, Н. А. Классификация дислокационных субструктур / Н. А. Конева, Э. В. Козлов, Л. И. Тришкина // Металлофизика. - 1991. - Т.13 (№ 10). - С. 49-58.

3. Кораблев, В. А. Влияние температуры закалки на процессы, протекающие при отпуске стали 35X4

В. А. Кораблев, А. П. Школенко // Термическая обработка и физика металлов. Вып. 9. Межвузовский сборник. - Свердловск: Изд-во УПИ им. С. М. Кирова, 1981. - С. 107-114.

4. Курдюмов, Г. В. Превращения в железе и стали / Г. В. Курдюмов, Л. М. Утевский, Р. И. Энтин. - М.: Наука, 1977.- 273 с.

5. Кутсар, А. Р. Изучение превращений при отпуске стали методом ядерного гамма-резонанса А. Р. Кутсар, Ю. А. Родионов, Г. Г. Исфандияров // Физика металлов и металловедение. - 1980. - Т. 49. C. $645-648$.

6. Лысак, Л. И. Физические основы термической обработки стали / Л. И. Лысак, Б. И. Николин. - Киев, 1975. $-304 \mathrm{c}$.

7. Новые материалы и технологии. Конструирование новых материалов и упрочняющих технологий В. Е. Панин, В. А. Клименов, С. Г. Псахье [и др.]; под ред. В. Е. Панина. - Новосибирск: Наука, 1993. $152 \mathrm{c}$.

8. Отчет по научно-исследовательской работе. Тема: В/д № 34-77 «Исследование механизма образования, формы, размеров и площади карбидной фазы при обычном отпуске и тепловой обработке в вакууме на износостойкость и долговечность шарнирных подшипников из стали 95Х18Ш» / рук. В. А. Кораблев; исполн. В. А. Кораблев [и др.]. - Тюмень: Тюменский индустриальный институт (ТИИ) им. Ленинского Комсомола, 1980. - 244 с.: № ГР 78003824.

9. Полянская, И. Л. Изучение процессов, протекающих в закаленных углеродистых сталях при низком отпуске: монография / И. Л. Полянская, В. А. Кораблев. - Тюмень: РИО ФГБОУ ВПО «ТюмГАСУ», 2015. $80 \mathrm{c}$.

10. Сальдау, П. Я. Метод электропроводности при высоких температурах / П. Я. Сальдау. - М.: АН СССР, 1952. - C. 54-67.

11. Федоров, В. А. Влияние отжига на кинетику процессов охрупчивания аморфных сплавов / В. А. Федоров, А. В. Яковлев, А. Н. Капустин // Металловедение и термическая обработка металлов. - 2008. № 8(638). - C. 39-41.

12. Черепин, В. Т. Экспериментальная техника в металловедении / В. Т. Черепин. - Киев, 1968. - 351 с. 